\title{
A INFLUÊNCIA DO TRATAMENTO TÉRMICO PÓS SOLDAGEM PARA ALÍVIO DE TENSÕES NA DUREZA DA SOLDA COM MATERIAL DE ADIÇÃO ER410NIMO *
}

\author{
Thiago Viana de Oliveira Turra ${ }^{1}$ \\ Alexandre Bueno ${ }^{2}$ \\ André de Albuquerque Vicente ${ }^{3}$ \\ Denise Crocce Romano Espinosa ${ }^{4}$ \\ Jorge Alberto Soares Tenório ${ }^{5}$
}

\section{Resumo}

Foi estudado o comportamento do resultado de dureza com o acréscimo de tempo de patamar de tratamento térmico para alívio de tensões, em juntas soldadas com processos MAG e TIG. Utilizou-se o metal base ASTM A743 CA6NM, um aço inoxidável martensítico usado na fabricação de rotores para geração de energia hidroelétrica, e o consumível de soldagem AWS A5.9 ER410NiMo. No processo MAG, foi usado o gás mistura de $96 \% \mathrm{Ar}+4 \% \mathrm{CO}_{2}$, e no processo TIG o gás $100 \%$ Ar. Para cada processo, foi soldado um corpo de prova, que foi cortado em sete fatias ao longo do comprimento. Observou-se redução na dureza do estado "como soldado" para o primeiro ciclo de oito horas de patamar. Nos demais ciclos a variação encontrada não tem significância dentro da dispersão da amostragem.

Palavras-chave: Aço Inoxidável martensítico; Processos de soldagem; Dureza; Tratamento térmico pós soldagem para alívio de tensões.

\section{THE INFLUENCE OF POST WELD HEAT TREATMENT FOR STRESS RELIEF ON HARDNESS OF WELD WITH ER410NIMO FILLER MATERIAL}

\section{Abstract}

The behavior of hardness result was studied with the increasing of holding time of a post weld heat treatment for stress relief, in joints welded by processes MAG and TIG. Was used ASTM A743 CA6NM base material, a martensitic stainless steel used for runner for hydropower generation fabrication, and the filler material AWS A5.9 ER410NiMo. On MAG process, was used a $96 \% \mathrm{Ar}+4 \% \mathrm{CO}_{2}$ gas mixture, and on TIG process a $100 \%$ Ar gas. For each process, was welded a test coupon, which was cutted in seven slices along its length. Was observed hardness reduction for the "as welded" condition to the first cycle of eight hours of holding time. On the other cycles, the variance found does not have significance within the sample dispersion.

Keywords: Martensitic stainless steel; Welding processes; Hardness; Post weld heat treating for stress relief.

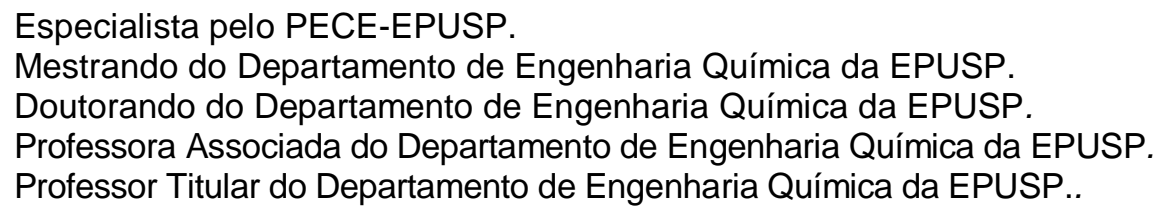




\section{INTRODUÇÃO}

Na fabricação de turbinas para geração de energia hidroelétrica, a liga mais usada atualmente é o aço inoxidável martensíticos do tipo CA6NM. [1] É uma liga de ferrocromo-níquel-molibdênio, podendo ser endurecida por tratamento térmico. É uma evolução do tipo CA15, tendo condições de resistência à corrosão semelhantes, mas devido à adição de níquel e molibdênio também possui resistência para trabalho com água do mar. Outra característica do CA6NM é a sua tenacidade e resistência à cavitação muito superiores a suas versões antigas. A facilidade em fundição de seções espessas o torna a primeira opção para a fabricação de turbinas hidráulicas para geração de energia. [2, 3]

Para realizar a soldagem destes aços, recomenda-se:

- Trabalhar com consumíveis de mesma composição química, geralmente o arame da classificação AWS A5.9 ER410NiMo;

- Executar a soldagem abaixo da temperatura Ms, deste modo permitindo à estrutura formada no resfriamento seja revenida pelos passes subsequentes;

- É necessário o tratamento térmico para alívio de tensões quando se deseja melhores propriedades de impacto e resistência à fratura. [4]

O ciclo de fabricação de uma turbina eventualmente necessita de soldagem em diversas etapas, e deste modo, algumas das soldagens presentes no componente passam por diversos ciclos de alívio de tensões.

O tratamento térmico para alívio de tensões é executado em temperaturas abaixo da temperatura de transformação $A C 1$ do material, mas suficiente para causar redução das propriedades mecânicas do material. No momento do patamar, as tensões residuais se sobressaem ao limite de escoamento, causando deformações na microestrutura e, deste modo, reduzindo estas tensões presentes no componente após a fabricação.

A dureza é uma das propriedades mecânicas dos materiais e está diretamente ligada à resistência mecânica. Como o tratamento térmico altera as propriedades mecânicas do material, consequentemente a dureza é alterada conforme o ciclo de tratamento a qual é submetida. A resistência mecânica é uma das propriedades que tornam o CA6NM viável para a fabricação de turbinas, então a mudança desta propriedade pode trazer grandes problemas práticos. [5]

\section{MATERIAIS E MÉTODOS}

\subsection{Processo de soldagem e preparação dos corpos de prova soldados:}

Para soldagem dos corpos de prova foram usados os processos MAG e TIG.

Foi usado o consumível AWS A5.9 ER410NiMo em forma de arame sólido com $\varnothing$ $1,2 \mathrm{~mm}$ para processo MAG e em varetas com $\varnothing 2,4 \mathrm{~mm}$ para processo TIG. No processo MAG foi usado o gás mistura de $96 \% \mathrm{Ar}+4 \% \mathrm{CO}_{2}$ com vazão de $16 \mathrm{l} / \mathrm{min}$. No processo TIG foi usado o gás $100 \% \operatorname{Ar}$ com vazão de $12 \mathrm{l} / \mathrm{min}$.

O equipamento MAG foi ajustado de modo a produzir arco estável, cujos parâmetros médios foram $252 \mathrm{~A}, 28 \mathrm{~V}, 16,42 \mathrm{~cm} / \mathrm{min}$, produzindo uma energia de soldagem média de 22,24 kJ/cm. O processo TIG por sua vez registrou $160 \mathrm{~A}, 13 \mathrm{~V}, 9 \mathrm{~cm} / \mathrm{min}$, produzindo uma energia de soldagem média de $12,84 \mathrm{~kJ} / \mathrm{cm}$.

As figuras 1 e 2 descrevem como os corpos de prova foram executados: 


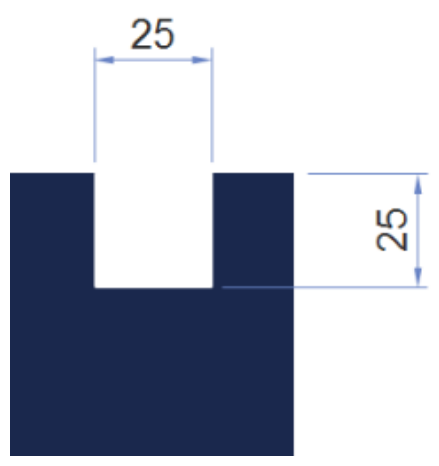

a)

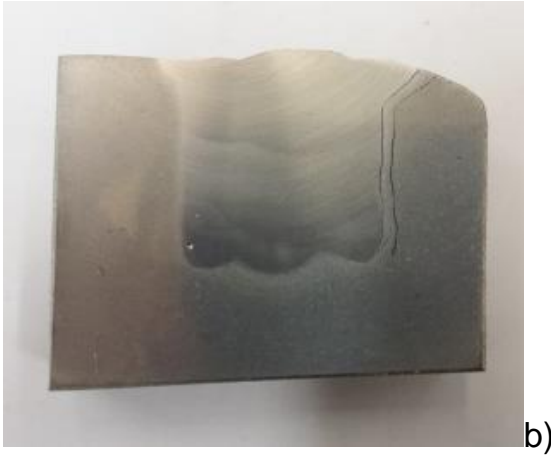

Figura 1 - a) esquema de execução dos corpos de prova b) corpo de prova soldado através de processo de soldagem MAG.

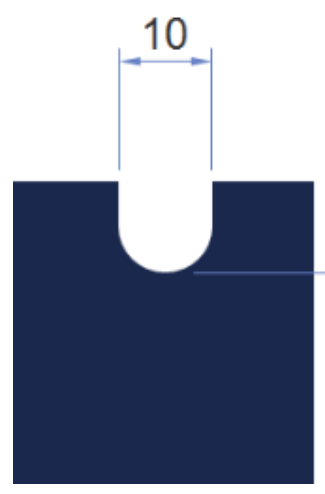

a)

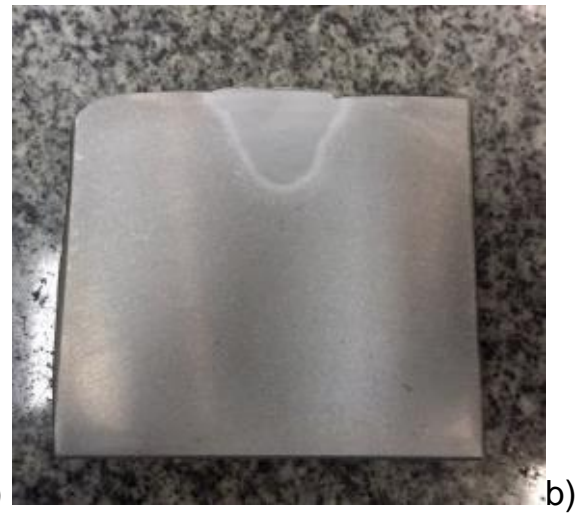

Figura 2 - a) esquema de execução dos corpos de prova b) corpo de prova soldado através de processo de soldagem TIG.

Para a confecção dos corpos de prova, utilizou-se como metal base blocos de aço inoxidável martensítico ASTM A743 tipo CA6NM, com $80 \mathrm{~mm}$ de espessura, $80 \mathrm{~mm}$ de altura e $190 \mathrm{~mm}$ de comprimento.

\subsection{Corte e preparação das amostras:}

Após a soldagem, os corpos de prova foram cortados em sete fatias com aproximadamente $15 \mathrm{~mm}$ de espessura, descartando os $25 \mathrm{~mm}$ iniciais e finais do comprimento do corpo de provas.
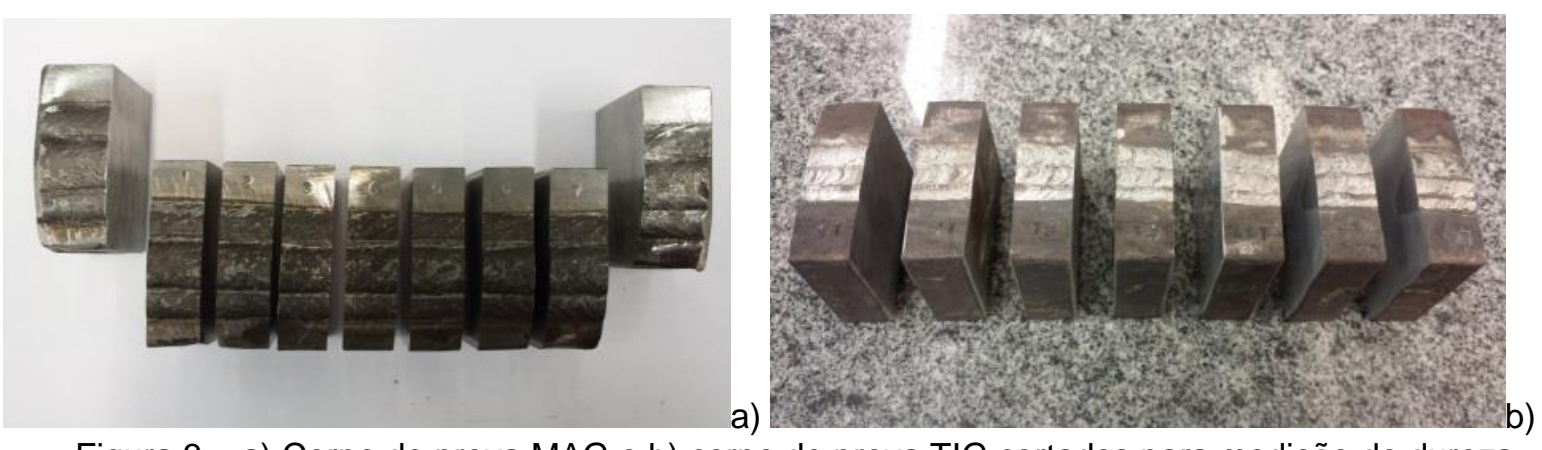

Figura 3 - a) Corpo de prova MAG e b) corpo de prova TIG cortados para medição de dureza. 


\subsection{Medição de dureza e tratamento térmico para alívio de tensões:}

Após o corte das amostras, as mesmas foram condicionadas para medição de dureza, realizando a retificação por usinagem para obter o paralelismo adequado, seguido de polimento com acabamento final por pasta de diamante com granulometria de $3 \mu \mathrm{m}$ e finalizado com ataque químico com reagente Vilella.

As medições de dureza foram executadas utilizando o método Vickers, com carga de 10 kgf, conforme norma ASME E92-82(2003)e2 [6]. A distribuição das medições ocorreu conforme a figura 4.

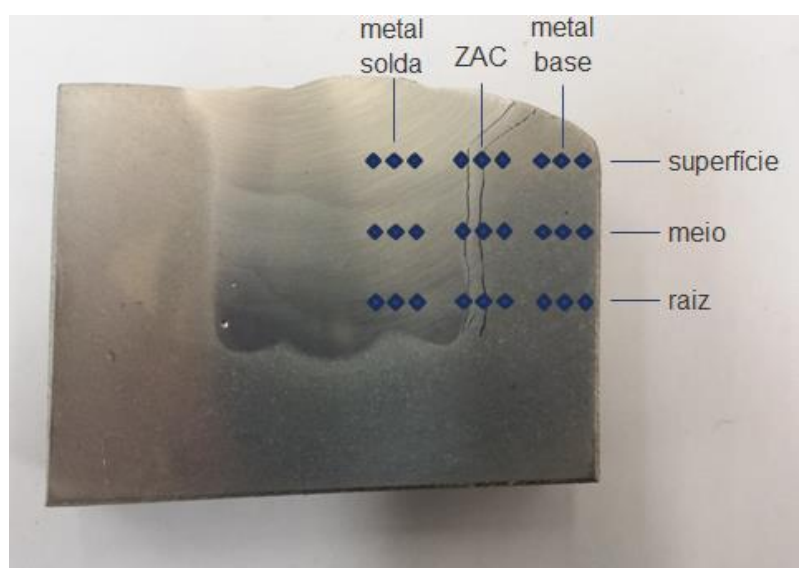

Figura 4 - Distribuição das medições de dureza HV10 nos corpos de prova

Após a realização das medições, as fatias foram submetidas ao ciclo de alívio de tensões para alívio de tensões. O alívio foi executado em um forno elétrico utilizando os seguintes parâmetros:

- Temperatura inicial do forno: $50^{\circ} \mathrm{C}$

- Taxa de aquecimento: $50^{\circ} \mathrm{C} / \mathrm{h}$

- Temperatura de patamar: $580 \pm 10^{\circ} \mathrm{C}$

- Tempo de patamar: 8 horas

- Taxa de resfriamento: $30^{\circ} \mathrm{C} / \mathrm{h}$

- Temperatura de abertura do forno: $150^{\circ} \mathrm{C}$

Após o ciclo de tratamento térmico, as amostras foram recondicionadas para medição de dureza. $O$ ciclo medição de dureza e tratamento térmico foi repetido 5 vezes, produzindo as seguintes condições de medição:

- 1 - Sem alívio de tensões ("como soldado")

- 2 - Com alívio de tensões com T =580 $\pm 10^{\circ} \mathrm{C} @ 8 \mathrm{~h}$

- 3 - Com alívio de tensões com T $=580 \pm 10^{\circ} \mathrm{C} @ 16 \mathrm{~h}$

- 4 - Com alívio de tensões com T=580 $\pm 10^{\circ} \mathrm{C} @ 24 \mathrm{~h}$

- 5 - Com alívio de tensões com T=580 $\pm 10^{\circ} \mathrm{C} @ 32 \mathrm{~h}$

- 6-Com alívio de tensões com T=580 $\pm 10^{\circ} \mathrm{C} @ 40 \mathrm{~h}$

No total, com 2 processos de soldagem (MAG e TIG), 6 ciclos de tratamento térmico (como soldado, 8h, 16h, 24h, 32h e 40h), 7 amostras de medição de dureza e 27 pontos de medição por amostra, soma-se um total de 2268 medições de dureza. 


\section{RESULTADOS E DISCUSSÃO}

Os dados foram avaliados com teste de normalidade Anderson-Darling para justificar o comparativo de valores médio, obtendo resultado positivo para todos os casos. [7] Deste modo, as tabelas abaixo apresentam o resumo dos valores médios coletados, seus desvios padrões e o valor de alteração em relação à mudança anterior.

Tabela 1 - Resultados para processo MAG - Metal solda

\begin{tabular}{|l|c|c|c|c|c|c|c|}
\hline Tempo de tratamento & Oh & $8 \mathrm{~h}$ & $16 \mathrm{~h}$ & $24 \mathrm{~h}$ & $32 \mathrm{~h}$ & $40 \mathrm{~h}$ \\
\hline Localização & \multicolumn{7}{|c|}{ Superfície - Metal solda } \\
\hline Dureza média & 366 & 299 & 289 & 293 & 294 & 295 \\
\hline Desvio padrão [\%] & $4,87 \%$ & $1,76 \%$ & $2,38 \%$ & $2,49 \%$ & $2,27 \%$ & $2,49 \%$ \\
\hline Alteração [\%] & - & $18,24 \%$ & $3,47 \%$ & $-1,65 \%$ & $-0,08 \%$ & $-0,62 \%$ \\
\hline \hline Localização & \multicolumn{7}{|c|}{ Meio - Metal solda } \\
\hline Dureza média & 363 & 299 & 287 & 292 & 294 & 299 \\
\hline Desvio padrão [\%] & $7,01 \%$ & $1,92 \%$ & $2,59 \%$ & $2,69 \%$ & $2,12 \%$ & $2,10 \%$ \\
\hline Alteração [\%] & - & $17,68 \%$ & $3,82 \%$ & $-1,49 \%$ & $-0,80 \%$ & $-1,64 \%$ \\
\hline \hline Localização & \multicolumn{7}{|c|}{ Raiz - Metal solda } \\
\hline Dureza média & 366 & 300 & 290 & 295 & 292 & 301 \\
\hline Desvio padrão [\%] & $4,88 \%$ & $2,36 \%$ & $2,56 \%$ & $2,89 \%$ & $2,03 \%$ & $1,85 \%$ \\
\hline Alteração [\%] & - & $18,01 \%$ & $3,33 \%$ & $-1,58 \%$ & $0,87 \%$ & $-2,94 \%$ \\
\hline
\end{tabular}

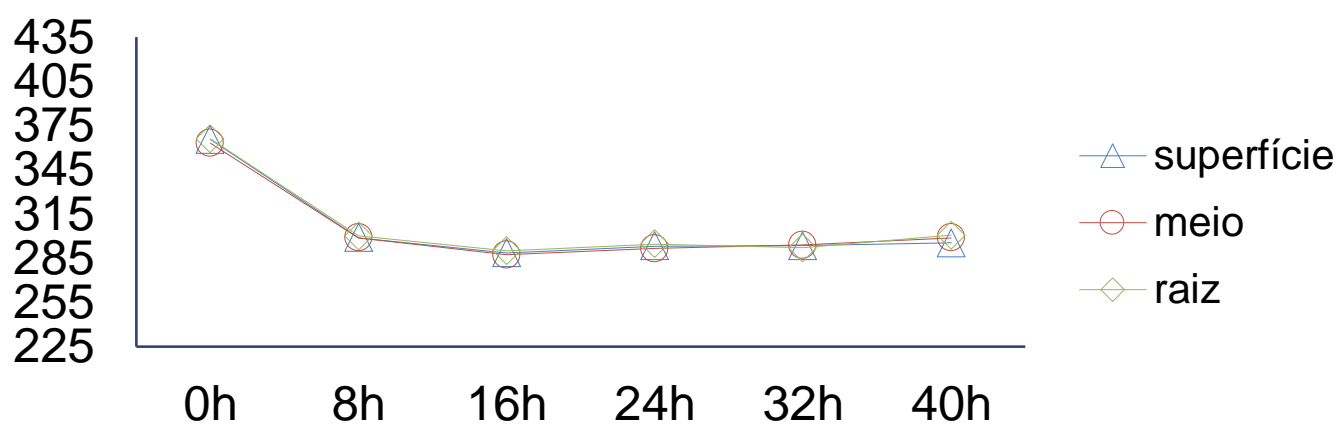

Figura 5 - Variação da dureza no metal de solda para processo MAG 
Tabela 2 - Resultados para processo MAG - ZAC

\begin{tabular}{|l|c|c|c|c|c|c|c|}
\hline Tempo de tratamento & Oh & $8 \mathrm{~h}$ & $16 \mathrm{~h}$ & $24 \mathrm{~h}$ & $32 \mathrm{~h}$ & $40 \mathrm{~h}$ \\
\hline Localização & \multicolumn{7}{|c|}{ Superfície - ZAC } \\
\hline Dureza média & 363 & 310 & 295 & 301 & 301 & 305 \\
\hline Desvio padrão [\%] & $4,21 \%$ & $3,08 \%$ & $3,10 \%$ & $2,65 \%$ & $2,41 \%$ & $2,06 \%$ \\
\hline Alteração [\%] & - & $14,53 \%$ & $5,02 \%$ & $-1,92 \%$ & $-0,21 \%$ & $-1,27 \%$ \\
\hline \hline Localização & \multicolumn{7}{|c|}{ Meio - ZAC } \\
\hline Dureza média & 363 & 314 & 297 & 302 & 304 & 306 \\
\hline Desvio padrão [\%] & $3,98 \%$ & $2,66 \%$ & $2,37 \%$ & $2,31 \%$ & $2,35 \%$ & $1,25 \%$ \\
\hline Alteração [\%] & - & $13,40 \%$ & $5,51 \%$ & $-1,69 \%$ & $-0,92 \%$ & $-0,50 \%$ \\
\hline \hline Localização & \multicolumn{7}{|c|}{ Raiz - ZAC } \\
\hline Dureza média & 351 & 314 & 298 & 300 & 300 & 305 \\
\hline Desvio padrão [\%] & $4,18 \%$ & $2,67 \%$ & $2,26 \%$ & $2,96 \%$ & $2,55 \%$ & $1,22 \%$ \\
\hline Alteração [\%] & - & $10,71 \%$ & $4,90 \%$ & $-0,46 \%$ & $-0,14 \%$ & $-1,81 \%$ \\
\hline
\end{tabular}

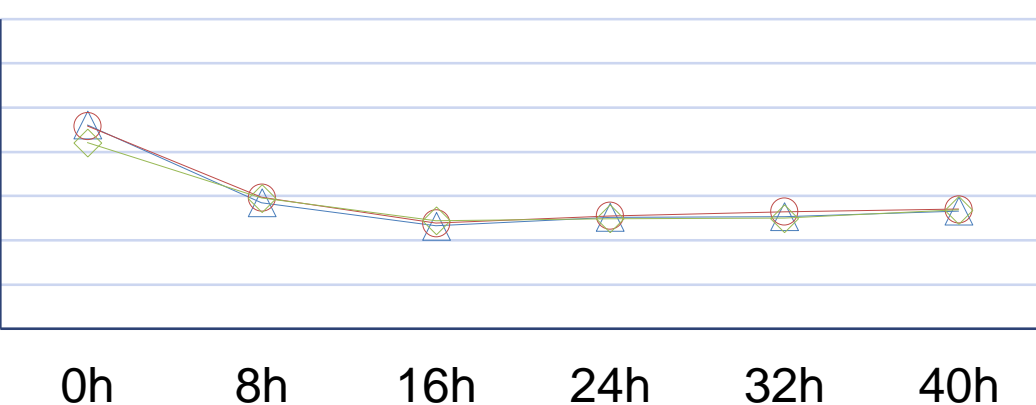

Oh $\quad 8 \mathrm{~h} \quad 16 \mathrm{~h} \quad 24 \mathrm{~h} \quad 32 \mathrm{~h} \quad 40 \mathrm{~h}$

Figura 6 - Variação da dureza na zona afetada pelo calor para processo MAG

Tabela 3 - Resultados para processo MAG - Metal base

\begin{tabular}{|l|c|c|c|c|c|c|}
\hline Tempo de tratamento & $0 \mathrm{~h}$ & $8 \mathrm{~h}$ & $16 \mathrm{~h}$ & $24 \mathrm{~h}$ & $32 \mathrm{~h}$ & $40 \mathrm{~h}$ \\
\hline Localização & \multicolumn{7}{|c|}{ Superfície - Metal base } \\
\hline Dureza média & 282 & 299 & 295 & 301 & 301 & 303 \\
\hline Desvio padrão [\%] & $5,86 \%$ & $3,60 \%$ & $3,00 \%$ & $2,94 \%$ & $2,11 \%$ & $2,37 \%$ \\
\hline Alteração [\%] & - & $-6,25 \%$ & $1,56 \%$ & $-2,02 \%$ & $0,00 \%$ & $-0,74 \%$ \\
\hline \hline Localização & \multicolumn{7}{|c|}{ Meio - Metal base } \\
\hline Dureza média & 280 & 301 & 296 & 300 & 299 & 306 \\
\hline Desvio padrão [\%] & $4,17 \%$ & $3,84 \%$ & $3,08 \%$ & $2,71 \%$ & $2,83 \%$ & $1,42 \%$ \\
\hline Alteração [\%] & - & $-7,78 \%$ & $1,66 \%$ & $-1,16 \%$ & $0,33 \%$ & $-2,41 \%$ \\
\hline \hline Localização & \multicolumn{7}{|c|}{ Raiz - Metal base } \\
\hline Dureza média & 280 & 303 & 296 & 302 & 301 & 305 \\
\hline Desvio padrão [\%] & $3,92 \%$ & $4,35 \%$ & $2,99 \%$ & $2,40 \%$ & $2,48 \%$ & $2,09 \%$ \\
\hline Alteração [\%] & - & $-8,13 \%$ & $2,33 \%$ & $-2,11 \%$ & $0,47 \%$ & $-1,58 \%$ \\
\hline
\end{tabular}




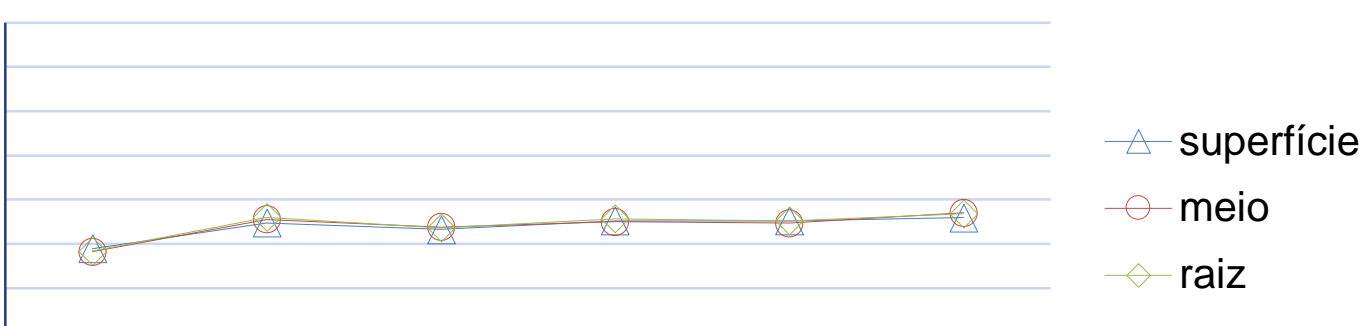

Oh $\quad 8 \mathrm{~h} \quad 16 \mathrm{~h} \quad 24 \mathrm{~h} \quad 32 \mathrm{~h} \quad 40 \mathrm{~h}$

Figura 7 - Variação da dureza no metal de base para processo MAG

Tabela 4 - Resultados para processo TIG - Metal solda

\begin{tabular}{|l|c|c|c|c|c|c|c|}
\hline Tempo de tratamento & Oh & $8 \mathrm{~h}$ & $16 \mathrm{~h}$ & $24 \mathrm{~h}$ & $32 \mathrm{~h}$ & $40 \mathrm{~h}$ \\
\hline Localização & \multicolumn{7}{|c|}{ Superfície - Metal solda } \\
\hline Dureza média & 346 & 311 & 305 & 309 & 310 & 311 \\
\hline Desvio padrão [\%] & $4,84 \%$ & $3,12 \%$ & $4,53 \%$ & $1,36 \%$ & $2,48 \%$ & $3,70 \%$ \\
\hline Alteração [\%] & & $9,98 \%$ & $2,02 \%$ & $-1,47 \%$ & $-0,18 \%$ & $-0,41 \%$ \\
\hline \hline Localização & \multicolumn{7}{|c|}{ Meio - Metal solda } \\
\hline Dureza média & 346 & 314 & 306 & 314 & 311 & 312 \\
\hline Desvio padrão [\%] & $5,17 \%$ & $3,28 \%$ & $2,98 \%$ & $2,28 \%$ & $2,12 \%$ & $2,42 \%$ \\
\hline Alteração [\%] & & $9,32 \%$ & $2,59 \%$ & $-2,49 \%$ & $0,84 \%$ & $-0,18 \%$ \\
\hline \hline Localização & \multicolumn{7}{|c|}{ Raiz - Metal solda } \\
\hline Dureza média & 345 & 316 & 308 & 317 & 310 & 312 \\
\hline Desvio padrão [\%] & $5,42 \%$ & $3,61 \%$ & $3,43 \%$ & $2,34 \%$ & $2,44 \%$ & $2,52 \%$ \\
\hline Alteração [\%] & & $8,29 \%$ & $2,65 \%$ & $-3,05 \%$ & $2,19 \%$ & $-0,57 \%$ \\
\hline
\end{tabular}

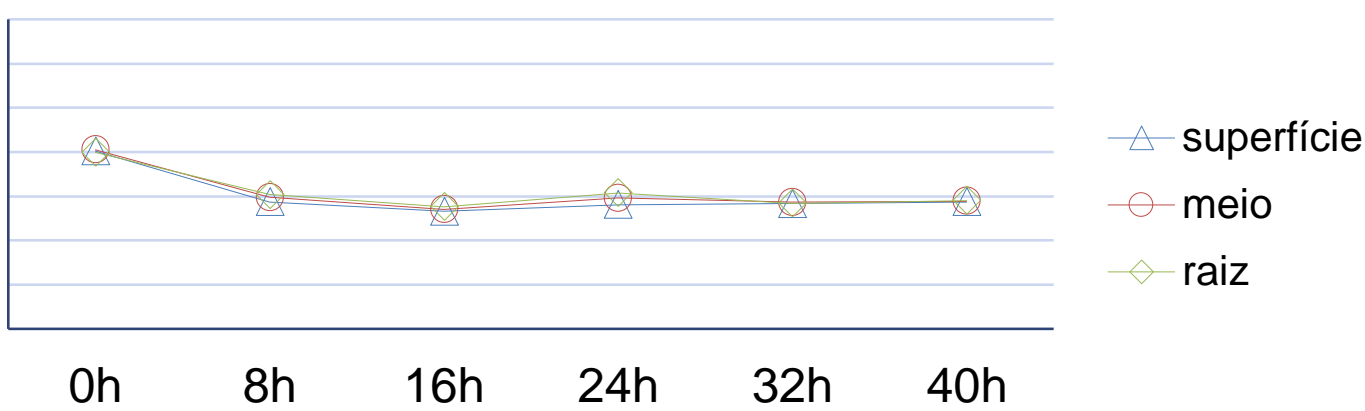

Figura 8 - Variação da dureza no metal de solda para processo TIG 
Tabela 5 - Resultados para processo TIG - ZAC

\begin{tabular}{|l|c|c|c|c|c|c|}
\hline Tempo de tratamento & Oh & $8 \mathrm{~h}$ & $16 \mathrm{~h}$ & $24 \mathrm{~h}$ & $32 \mathrm{~h}$ & $40 \mathrm{~h}$ \\
\hline Localização & \multicolumn{7}{|c|}{ Superfície - ZAC } \\
\hline Dureza média & 363 & 310 & 295 & 301 & 301 & 305 \\
\hline Desvio padrão [\%] & $4,21 \%$ & $3,08 \%$ & $3,10 \%$ & $2,65 \%$ & $2,41 \%$ & $2,06 \%$ \\
\hline Alteração [\%] & - & $14,53 \%$ & $5,02 \%$ & $-1,92 \%$ & $-0,21 \%$ & $-1,27 \%$ \\
\hline \hline Localização & \multicolumn{7}{|c|}{ Meio - ZAC } \\
\hline Dureza média & 363 & 314 & 297 & 302 & 304 & 306 \\
\hline Desvio padrão [\%] & $3,98 \%$ & $2,66 \%$ & $2,37 \%$ & $2,31 \%$ & $2,35 \%$ & $1,25 \%$ \\
\hline Alteração [\%] & - & $13,40 \%$ & $5,51 \%$ & $-1,69 \%$ & $-0,92 \%$ & $-0,50 \%$ \\
\hline \hline Localização & \multicolumn{7}{|c|}{ Raiz - ZAC } \\
\hline Dureza média & 351 & 314 & 298 & 300 & 300 & 305 \\
\hline Desvio padrão [\%] & $4,18 \%$ & $2,67 \%$ & $2,26 \%$ & $2,96 \%$ & $2,55 \%$ & $1,22 \%$ \\
\hline Alteração [\%] & - & $10,71 \%$ & $4,90 \%$ & $-0,46 \%$ & $-0,14 \%$ & $-1,81 \%$ \\
\hline
\end{tabular}

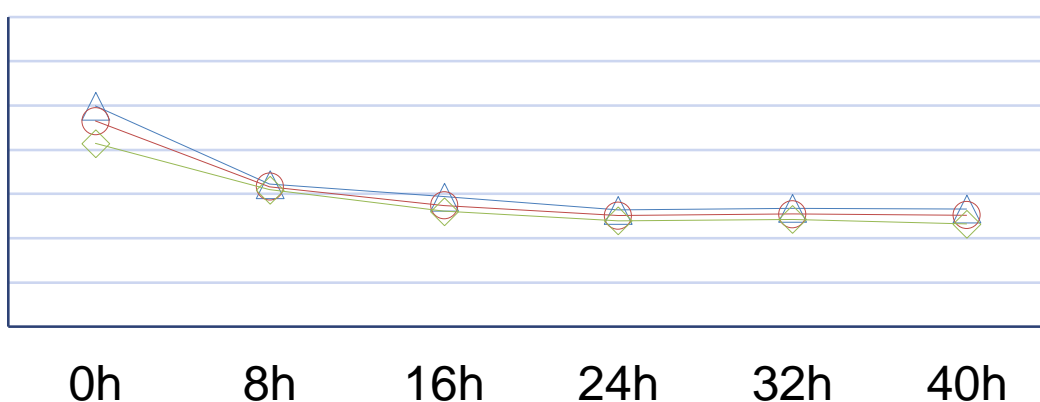

Oh $\quad 8 \mathrm{~h} \quad 16 \mathrm{~h} \quad 24 \mathrm{~h} \quad 32 \mathrm{~h} \quad 40 \mathrm{~h}$

Figura 9 - Variação da zona afetada pelo calor para processo TIG

Tabela 6 - Resultados para processo TIG - Metal base

\begin{tabular}{|l|c|c|c|c|c|c|}
\hline Tempo de tratamento & $0 \mathrm{~h}$ & $8 \mathrm{~h}$ & $16 \mathrm{~h}$ & $24 \mathrm{~h}$ & $32 \mathrm{~h}$ & $40 \mathrm{~h}$ \\
\hline Localização & \multicolumn{7}{|c|}{ Superfície - Metal base } \\
\hline Dureza média & 282 & 299 & 295 & 301 & 301 & 303 \\
\hline Desvio padrão [\%] & $5,86 \%$ & $3,60 \%$ & $3,00 \%$ & $2,94 \%$ & $2,11 \%$ & $2,37 \%$ \\
\hline Alteração [\%] & - & $-6,25 \%$ & $1,56 \%$ & $-2,02 \%$ & $0,00 \%$ & $-0,74 \%$ \\
\hline \hline Localização & \multicolumn{7}{|c|}{ Meio - Metal base } \\
\hline Dureza média & 280 & 301 & 296 & 300 & 299 & 306 \\
\hline Desvio padrão [\%] & $4,17 \%$ & $3,84 \%$ & $3,08 \%$ & $2,71 \%$ & $2,83 \%$ & $1,42 \%$ \\
\hline Alteração [\%] & - & $-7,78 \%$ & $1,66 \%$ & $-1,16 \%$ & $0,33 \%$ & $-2,41 \%$ \\
\hline \hline Localização & \multicolumn{7}{|c|}{ Raiz - Metal base } \\
\hline Dureza média & 280 & 303 & 296 & 302 & 301 & 305 \\
\hline Desvio padrão [\%] & $3,92 \%$ & $4,35 \%$ & $2,99 \%$ & $2,40 \%$ & $2,48 \%$ & $2,09 \%$ \\
\hline Alteração [\%] & - & $-8,13 \%$ & $2,33 \%$ & $-2,11 \%$ & $0,47 \%$ & $-1,58 \%$ \\
\hline
\end{tabular}




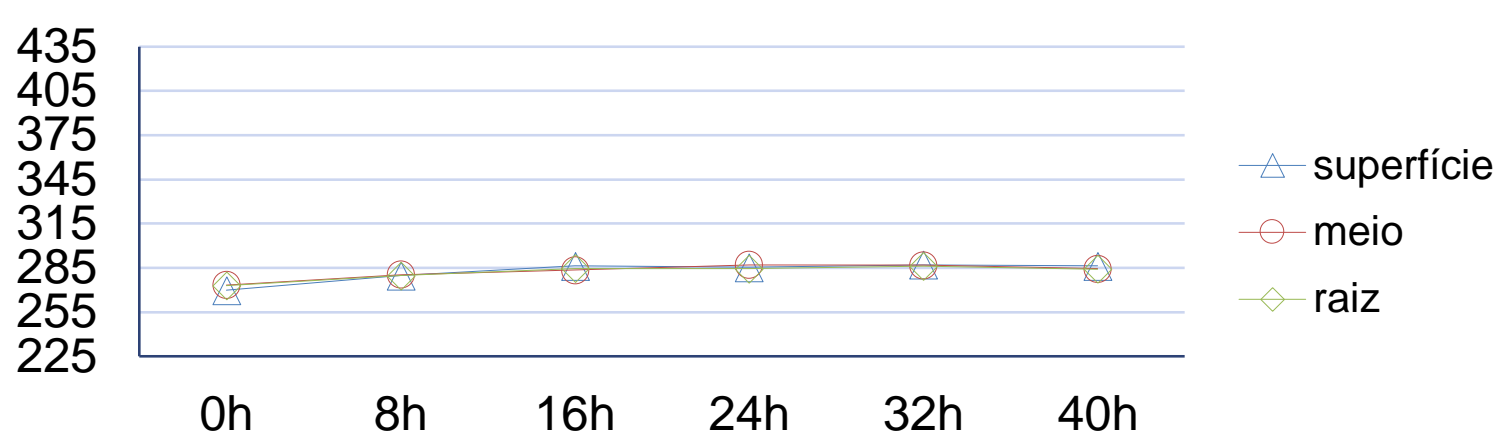

Figura 10 - Variação da dureza no metal de base para processo MAG

Pelos resultados, é possível verificar uma redução da dureza, no metal de solda e na ZAC, da condição "como soldado" para o primeiro ciclo de tratamento térmico.

Para o processo MAG, esta redução é da ordem entre 10 e $20 \%$ do valor original. No metal base houve um aumento após o primeiro ciclo, da ordem de $10 \%$ do valor original.

Para o processo TIG, esta redução é da ordem entre 10 e $15 \%$ do valor original. No metal base o aumento observado é da mesma ordem do processo MAG.

Nos demais ciclos de tratamento térmico, de $16 \mathrm{~h}, 24 \mathrm{~h}, 36 \mathrm{~h}$ e $40 \mathrm{~h}$, as variações de dureza média registradas estão dentro do desvio padrão, representando deste modo um comportamento estável.

Este efeito ocorre pois, durante o resfriamento da soldagem, como o processo de soldagem eleva a temperatura na zona de fusão e na zona afetada pelo calor a pontos acima da temperatura de transformação metalúrgica da liga ( $A C 1)$, alguma martensita da microestrutura resfria como martensita primária (não-revenida), a qual possui entre outras propriedades elevada dureza. Esta martensita primária e causadora do aumento da dureza no estado como soldado é então coalescida durante o processo de tratamento térmico para alívio de tensões, realizado abaixo da $A C 1$, mas com temperatura suficiente para reduzir a dureza desta parcela de martensita primária. [4]

\section{CONCLUSÃO}

É possível concluir que o primeiro ciclo de 8 horas de tratamento térmico para alívio de tensões reduz a dureza em 10 a 20 \% em relação ao estado "como soldado".

Adicionalmente, observou-se que os ciclos subsequentes não reduzem ou aumentam a dureza, pois a variação dos valores está dentro do desvio padrão da amostragem.

\section{Agradecimentos}

A Voith Hydro e seus gestores Alexandre Bueno e Leonardo Nuzzi pelo suporte durante toda a execução do projeto. Aos colegas de trabalho Flavio Gonçalves, Paulo Carvalho, Samuel Fernandes, Fabrício Ataíde, Dielson Silva e José Pestana por todo acompanhamento e execução dos testes.

Aos Profs. Jorge Tenório, Manuel Saraiva Clara e Andre Vicente pelo apoio, suporte técnico e acadêmico durante o desenvolvimento e elaboração do projeto. 


\section{REFERÊNCIAS}

1. THIBAULT, Denis et al. Residual stress characterization in low transformation temperature $13 \% \mathrm{Cr}-4 \% \mathrm{Ni}$ stainless steel weld by neutron diffraction and the contour method. Materials Science and Engineering: A, v. 527, n. 23, p. 62056210, 2010.

2. MODENESI, P. J. Soldabilidade dos Aços Inoxidáveis - SENAI-SP, Coleção Tecnologia da Soldagem, Vol. 1, 2001.

3. HANDBOOK, Steel Casting. Supplement 8, High Alloy Data Sheets Corrosion Series. Steel Founders Society of America, 2004.

4. HENKE, Sérgio L. et al. Especificação de Procedimentos de Reparo por Soldagem de Aços Inoxidáveis Martensíticos Macios Sem Tratamento Térmico Posterior, XXIV Encontro Nacional de Tecnologia da Soldagem. In: XI Congresso Latino-Americano e V İbero-Americano de Soldagem. 1998.

5. IWABUCHI, Yoshitaka. Temper embrittlement of type $13 \mathrm{Cr}-4 \mathrm{Ni}$ cast steel. Transactions of the Iron and Steel Institute of Japan, v. 27, n. 3, p. 211-217, 1987.

6. ASTM E92-82. Standard Test Method for Vickers Hardness of Metallic Materials. 1982.

7. MINITAB, Inc. MINITAB release 17: statistical software for windows. Minitab Inc, USA, 2014. 